\title{
Endoscopic versus microscopic transsphenoidal surgery in the treatment of pituitary tumors: systematic review and meta-analysis of randomized and non-randomized controlled trials
}

Rodrigo V. S. Bastos', Carla Maria D. M. Silva', Jose Vicente Tagliarini², Marco Antonio Zanini ${ }^{3}$, Flavio R. Romero ${ }^{3}$, Cesar Luiz Boguszewski ${ }^{4}$, Vania dos Santos Nunes ${ }^{1}$

\begin{abstract}
We conducted a systematic review and meta-analysis of randomized and non-randomized controlled trials that compared pure endoscopic with microscopic transsphenoidal surgery (TSS) in the resection of pituitary tumors. Embase, PubMed, Lilacs, and Central Cochrane were used as our data sources. The outcomes were total tumor resection, achievement of biochemical control of functioning adenomas, hospital stay and surgery complications. The randomized trials were analyzed using the Grading of Recommendations Assessment, Development, and Evaluation (GRADE) approach. Two randomized and three prospective controlled non-randomized studies were included. Two studies, including 68 patients, evaluated total tumor resection and the meta-analysis did not show differences between the groups [RR: $1.45(95 \% \mathrm{Cl}: 0.87,2.44)$ ]. Three studies involving 65 patients analyzed the achievement of biochemical control and no statistical difference was found [RR: 0.94 (95\% Cl: 0.7 , 1.26)]. All five studies compared the frequency of postoperative complications between intervention and control group and meta-analysis favored for a low rate of postoperative complications in the endoscopic TSS group [(RR: 0.37 (95\% Cl: $0.16,0.83)$ ]. Due to the low evidence level and low number of observations, the results of our meta-analysis should not be viewed as a final proof of inferiority or superiority of one approach in relation to the other. More data including higher numbers of observations are needed. Arch Endocrinol Metab. 2016;60(5):411-9
\end{abstract}

Keywords

Pituitary tumor; surgical endoscopy; neurosurgical procedure; review; systematic
1 Departamento de Clínica Médica, Faculdade de Medicina de Botucatu, Universidade Estadual Paulista (Unesp), Botucatu, SP, Brasil ${ }^{2}$ Departamento de Oftalmologia e Otorrinolaringologia, Faculdade de Medicina de Botucatu, Universidade Estadual Paulista (Unesp), Botucatu, SP, Brasil ${ }^{3}$ Departamento de Neurologia, Psiquiatria e Psicologia, Faculdade de Medicina de Botucatu,

Universidade Estadual Paulista (Unesp), Botucatu, SP, Brasil

${ }^{4}$ Departamento de Clínica Médica, Divisão de Endocrinologia, Serviço de Endocrinologia e Metabologia (SEMPR), Universidade Federal do Paraná (UFPR), Curitiba, PR, Brasil

Correspondence to: Vania dos Santos Nunes Departamento de Clínica Médica, Faculdade de Medicina de Botucatu Universidade Estadual Paulista Distrito de Rubião Junior $\mathrm{s} / \mathrm{n}^{\circ}$ 18618-970 - Botucatu, SP, Brasil vsnunes@fmb.unesp.br

Received on Sept/11/2015 Accepted on Apr/29/2016

DOI: 10.1590/2359-3997000000204

\section{INTRODUCTION}

$\mathrm{T}$ ranssphenoidal surgery (TSS) is the treatment of choice for most functioning and nonfunctioning pituitary tumors. The microscopic technique is a traditional and well-established procedure that has been successfully applied for removal of pituitary adenomas. Most available data about the short- and long-term outcomes of TSS are derived from this modality of surgery. In the 1990s, a distinct impulse came from the otorhinolaryngologists, with the use of the endoscope in functional endoscopic sinus surgery, disclosing the pathway to the sella turcica and the endoscopic approach for resection of pituitary tumors either alone or as an adjunct to the microneurosurgery.
Microscopic TSS can be performed via sublabial or endonasal transeptal approach. The latter has a slightly smaller field of view in comparison with the former, but it has the advantages of being less painful and not requiring postoperative packing (1). In the endoscopic technique, a rigid endoscope is used to get into the sphenoid sinus and the sella turcica through both nostrils. Some experienced neurosurgeons and otorhinolaryngologists have changed to the endoscopic surgery, claiming that this procedure is safer, less invasive, and allows a wider view of the sella turcica, improving tumor resection rates (1).

Studies comparing endoscopic with microscopic TSS have produced inconsistent results, either showing 
no difference between them (2-4) or favoring the new technique $(5,6)$. The main reasons for these discrepancies include comparisons of retrospective results of microscopic TSS versus prospective results of endoscopic TSS and the experience of the surgical teams with the different procedures. Thus, a careful analysis of each series reported on the literature is essential before asserting the superiority of one technique over the other.

The aim of the present study was to perform a systematic review and meta-analysis of randomized and non-randomized controlled trials that compared pure endoscopic with microscopic TSS in the resection of pituitary tumors. Our hypothesis was that endoscopic TSS would be safer and more effective than the microscopic technique in the management of pituitary tumors in experienced hands.

\section{MATERIALS AND METHODS}

We have included randomized, non-randomized, or quasi-randomized controlled trials that were carried out to compare endoscopic TSS (intervention group) with microscopic TSS (comparison group) involving adult patients with acromegaly, Cushing's disease, nonfunctioning pituitary adenomas (NFPA), prolactinomas resistant to dopamine agonists or other pituitary-related tumors.

The primary postoperative outcomes analyzed in our study included total tumor resection, achievement of biochemical control of functioning adenomas and frequency of postoperative complications, such as: cerebrospinal fluid (CSF) leak, temporary or permanent diabetes insipidus, hypopituitarism, hypothyroidism, hypocortisolism, sinusitis, meningitis, nasal synechiae, saddle nose, syndrome of inappropriate antidiuretic hormone secretion (SIADH), hyposmia, anosmia, blood loss, massive nasal bleeding, wound disruption and vision decline. Secondary outcomes were quality of life, costs, duration of postoperative hospital stay (days) and operative time.

We searched the following electronic databases: Embase (1980-2014), PubMed (1966-2014), Lilacs (1982-2014) and the Cochrane Central Register of Controlled Trials (CENTRAL, the Cochrane Library, issue 2014). Ongoing clinical trials on the ClinicalTrials. gov website, in conferences, hand-searches and specialists in this field were also consulted. The Medical Subject Heading ( $\mathrm{MeSH})$ terms used included "Acromegaly", "Pituitary ACTH Hypersecretion",
"Pituitary Neoplasms", "Hyperpituitarism”, "Endoscopic Transsphenoidal Surgery", "Microscopic Transsphenoidal Surgery". There was no language or year restriction.

Two reviewers (RVSB and JVT) independently screened the titles and abstracts identified by the literature search and the studies potentially eligible for inclusion in the review were selected for complete reading. In case of disagreements, there was a debate between the reviewers and a third party (VSN) before the final decision.

For each trial, we assigned risk of bias taking in consideration quality scores for random sequence generation, allocation concealment, blinding of outcomes and incomplete outcome data. We used the criteria described in the Cochrane Reviewers' Handbook (7) to classify these scores in adequate (low risk of bias), unclear, and inadequate (high risk of bias).

We performed the meta-analysis using Review Manager 5.3 software. For dichotomous outcomes, relative risk was calculated with a 95\% confidence interval and we expressed continuous variables as weighted mean difference along with their 95\% confidence intervals. Potential causes of heterogeneity among the studies were also analyzed. The $\mathrm{I}^{2}$ statistic was used to measure the proportion of statistical heterogeneity for each outcome. When the data were homogeneous, we undertook a fixed-effect analysis. However, in the presence of heterogeneity $\left(\mathrm{I}^{2}>0\right)$, the analysis was performed in a random-effect model. The sensitivity analysis was also performed by excluding non-randomized controlled trials.

The quality of evidence per outcome measurement was graded according to the guidelines of the GRADE (Grading of Recommendations Assessment, Development, and Evaluation) Working Group $(8,9)$. The confidence of GRADE system decreases if studies have major limitations that may interfere on the estimates of the treatment effect (8). These limitations include risk of bias at each included study, and GRADE also considers inconsistency, indirectness, imprecision and publication bias of each evaluated outcome. Randomized studies have risk of bias when they failure to conceal allocation, failure to blind, loss to follow-up, and failure to appropriately consider the intention to treat principle (10). Inconsistency is related to heterogeneity of the results, indirectness compares whether the interventions are delivered to the adequate populations, imprecision refers to what extent our confidence in the estimated effect is adequate to 
support a particular decision (confidence intervals) and publication bias should be suspected when available evidence comes from a number of small studies $(11,12)$, most of which have been pharmaceutical industry sponsored $(13,14)$.

\section{RESULTS}

Our search identified 1238 references (Figure 1). Nineteen articles were potentially eligible for inclusion in our review, and from these 12 were excluded because they involved retrospective comparisons $(2,3,5,15-23)$ and two were excluded because they were publication of case series $(24,25)$. Five publications were included in the final analysis $(4,6,26-28)$.

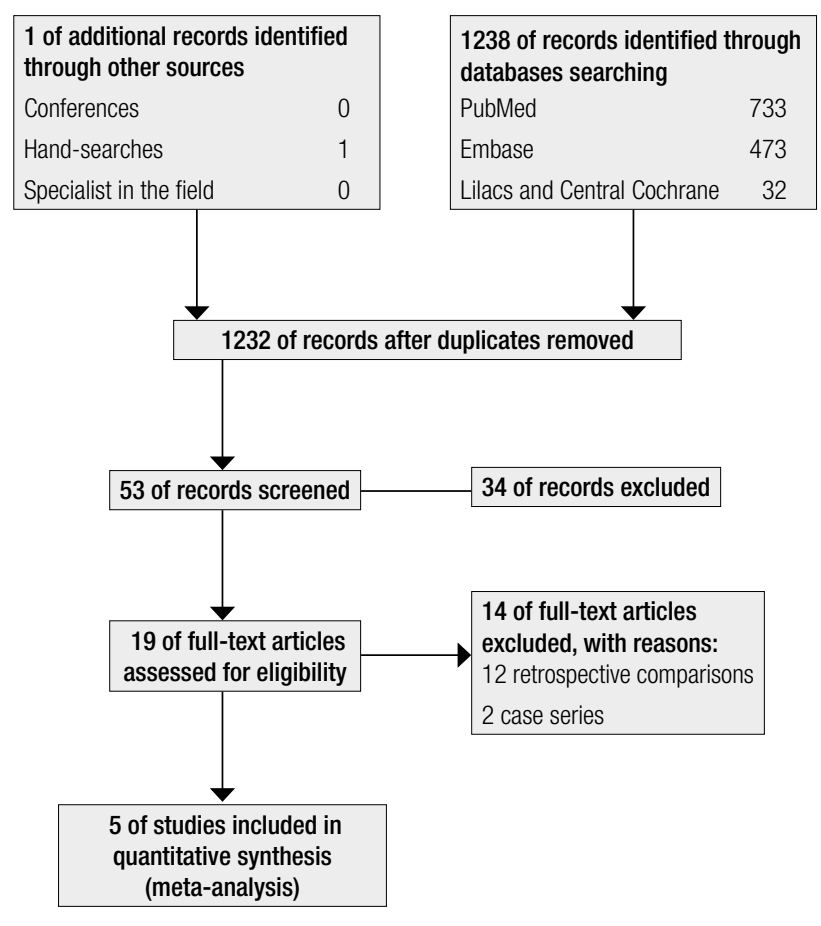

Figure 1. Flowchart for identifying eligible studies

Five studies included in the meta-analysis involved a total of 328 participants; two were randomized controlled trials $(6,26)$ and three were non-randomized controlled trials $(4,27,28)$. The main characteristics of the enrolled patients are presented in Table 1.

Jain and cols. (26) randomized 20 patients with pituitary adenomas (9 NFPA, 5 acromegaly, 3 prolactinomas, 2 Cushing's disease, 1 Nelson syndrome) to endoscopic or microscopic TSS. Most patients had macroadenoma. An endoscopic rhinologist performed the endoscopic TSS and a neurosurgeon performed the microscopic TSS; both were dedicated surgeons who have been operating for more than 15 years. Primary outcomes were complete tumor removal, mean operative time, blood loss, and CSF leak. All patients were subjected to a magnetic resonance imaging (MRI) three months after surgery that showed the same complete tumor removal rate in both groups.

Cho and Liau (6) randomized to endoscopic or microspic TSS 44 patients with prolactinoma who were operated due to intolerance to bromocriptine or visual deficits. The groups had similar baseline characteristics, the mean follow up was 3.5 years and the main outcomes were normal prolactin levels, normal menstrual cycle, no galactorrhea, visual field improvement, operative time, hospital stay and complications.

In a prospective study performed in Phoenix, Arizona, 166 patients were assigned to one of the study groups according to surgeon preference: 67 to endoscopic (43 NFPA, 7 acromegaly, 7 prolactinomas, 3 Cushing's disease, 7 other) and 99 to microscopic TSS (57 NFPA, 13 acromegaly, 11 prolactinomas, 7 Cushing's disease, 11 other (Rathke's cleft cyst, meningioma, pituitary cyst) (4). One surgeon performed all microscopic TSS and another one all the endoscopic TSS. The secondary outcomes were length of stay in the hospital (days) and complications (temporary or permanent diabetes insipidus, CSF leak, hyponatremia, cardiac dysrhythmia, respiratory failure, delirium tremens, heart palpitations, vision decline, and meningitis).

Kahilogullari and cols. (28) performed a nonrandomized controlled study comparing olfactory functions between 50 patients operated by endoscopic or microscopic TSS (44 pituitary adenomas (30 hormone-active and 14 NFPA), 3 fibrous dysplasia, 1 Rathke cyst, 1 chordoma, 1 hypophysitis). The Smell Diskettes Olfaction Test was applied before and 1 and 6 months after the surgery to evaluate olfactory outcomes. The authors also studied incidence of CSF leak. In the endoscopic group, they observed only two patients with hyposmia, while in the microscopic group, 13 patients developed anosmia and 5 anosmia.

Enseñat and cols. (27) performed a prospective, non-randomized study, to compare the TSS techniques in relation to the total and subtotal tumor resection, surgical complications and time of post-operative hospitalization. They included 50 patients who had sellar lesions with different grades of invasiveness of the cavernous sinus (47 pituitary adenomas, 3 Rathke cyst). 
Table 1. Main characteristics of the enrolled patients and risk of bias in the five included studies

\begin{tabular}{|c|c|c|c|c|c|c|c|}
\hline \multirow[b]{2}{*}{ Study/Year } & \multirow{2}{*}{$\begin{array}{l}\text { Type of study } \\
\text { number of } \\
\text { patients }\end{array}$} & \multirow[b]{2}{*}{$\begin{array}{l}\text { Inclusion } \\
\text { criteria }\end{array}$} & \multirow[b]{2}{*}{ Outcomes } & \multicolumn{4}{|c|}{ Risk of Bias } \\
\hline & & & & Randomization & $\begin{array}{l}\text { Blinding of } \\
\text { outcome } \\
\text { assessment }\end{array}$ & Allocation & $\begin{array}{c}\text { Incomplete } \\
\text { outcome } \\
\text { data }\end{array}$ \\
\hline Jain, 2007 & $\begin{array}{l}\text { Randomized } \\
10 / 10\end{array}$ & $\begin{array}{l}\text { Patients with } \\
\text { pituitary } \\
\text { adenoma }\end{array}$ & $\begin{array}{l}\text { Complete tumor resection, } \\
\text { achievement of biochemical control of } \\
\text { functioning adenomas, postoperative } \\
\text { complications, operative time }\end{array}$ & $\begin{array}{l}\text { Appropriate } \\
\text { (low risk) }\end{array}$ & $\begin{array}{l}\text { No mentioned } \\
\text { (unclear) }\end{array}$ & $\begin{array}{l}\text { No mentioned } \\
\text { (unclear) }\end{array}$ & $\begin{array}{c}\text { No } \\
\text { (low risk) }\end{array}$ \\
\hline Enseñat, 2009 & $\begin{array}{c}\text { Prospective } \\
\text { Non-randomized } \\
25 / 23\end{array}$ & $\begin{array}{l}\text { Patients with } \\
\text { pituitary } \\
\text { adenoma }\end{array}$ & $\begin{array}{l}\text { Complete tumor restriction, } \\
\text { achievement of biochemical control of } \\
\text { functioning adenomas, postoperative } \\
\text { complications, hospital stay }\end{array}$ & $\begin{array}{c}\text { No } \\
\text { (high risk) }\end{array}$ & $\begin{array}{l}\text { No mentioned } \\
\text { (unclear) }\end{array}$ & No applicable & $\begin{array}{c}\text { No } \\
\text { (low risk) }\end{array}$ \\
\hline Cho, 2002 & $\begin{array}{l}\text { Randomized } \\
\text { 22/22 }\end{array}$ & $\begin{array}{l}\text { Patient with } \\
\text { prolactinoma } \\
\text { and with } \\
\text { intolerance to } \\
\text { bromocriptin }\end{array}$ & $\begin{array}{c}\text { Visual field, achievement of } \\
\text { biochemical control of functioning } \\
\text { adenomas, postoperative } \\
\text { complications, hospital stay, operative } \\
\text { time }\end{array}$ & $\begin{array}{l}\text { No mentioned } \\
\text { (unclear) }\end{array}$ & $\begin{array}{l}\text { No mentioned } \\
\text { (unclear) }\end{array}$ & $\begin{array}{l}\text { No mentioned } \\
\text { (unclear) }\end{array}$ & $\begin{array}{c}\text { No } \\
\text { (low risk) }\end{array}$ \\
\hline Little, 2014 & $\begin{array}{c}\text { Prospective } \\
\text { Non-randomized } \\
67 / 99\end{array}$ & $\begin{array}{l}\text { Patients with } \\
\text { pituitary tumor }\end{array}$ & $\begin{array}{l}\text { Hospital charges, postoperative } \\
\text { complications, hospital stay, }\end{array}$ & $\begin{array}{c}\text { No } \\
\text { (high risk) }\end{array}$ & $\begin{array}{l}\text { No mentioned } \\
\text { (unclear) }\end{array}$ & No applicable & $\begin{array}{l}3 \text { patients } \\
\text { (low risk) }\end{array}$ \\
\hline $\begin{array}{l}\text { Kahilogullari, } \\
2013\end{array}$ & $\begin{array}{c}\text { Prospective } \\
\text { Non-randomized } \\
25 / 25\end{array}$ & $\begin{array}{l}\text { Patients with } \\
\text { pituitary tumor }\end{array}$ & Postoperative complications & $\begin{array}{c}\text { No } \\
\text { (high risk) }\end{array}$ & $\begin{array}{l}\text { No mentioned } \\
\text { (unclear) }\end{array}$ & No applicable & $\begin{array}{c}\text { No } \\
\text { (low risk) }\end{array}$ \\
\hline
\end{tabular}

The risk of bias (random sequence generation, allocation concealment, blinding of outcome assessment and incomplete outcome data) of five included studies are presented in Table 1 .

\section{Meta-analysis}

Two studies evaluated total tumor resection $(26,27)$; the meta-analysis did not show significant difference between the groups [RR: 1.45; (95\% CI: 0.87, 2.44)] (Figure 2). Three studies $(6,26,27)$ analyzed achievement of biochemical control of functioning pituitary adenomas and, again, no statistical difference was found between the intervention and comparison groups [RR: 0.94; (95\% CI: 0.7, 1.26)] (Figure 3A).

Three studies assessed the duration of postoperative hospital stay $(4,6,27)$, but only two mentioned standard deviation (SD) and could be included in the meta- analysis $(4,27)$. The result was heterogeneous (92\% $\left(\mathrm{I}^{2}\right)$ ), with one study favoring the intervention group and the other one showing no difference between the groups [MD: - 1.26 (95\% CI: $-4.1,1.59)$ ].

All five studies compared frequency of postoperative complications between intervention and control group and our meta-analysis favored for a low rate of postoperative complications in the endoscopic TSS group [(RR: 0.37; (95\% CI: 0.16, 0.83)] (Figure 4A).

Only Little and cols. (4) evaluated total hospital charges, and there was no statistical difference between the groups $(\$ 74,703 \pm \$ 15,142$ for microscopic surgery, $\$ 72,311 \pm \$ 16,576$ for endoscopic surgery; $p=0.33$ ). Hospital charges did not differ significantly by category, with the exception of higher charges for pathology in the microscopic surgery group $(\$ 6,46 \pm 2,605$ for endoscopic and $\$ 8,626 \pm 3,650$ for microscopic, $\mathrm{p}<0.001)$.

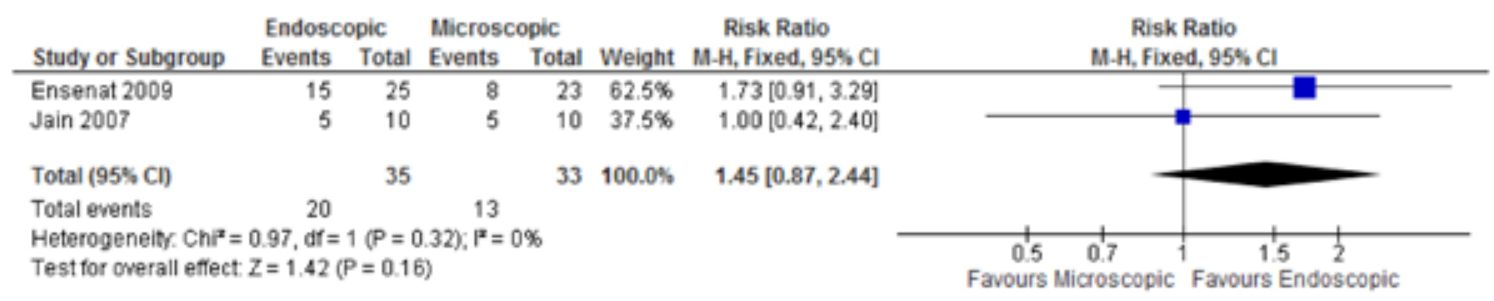

Figure 2. Meta-analysis of total tumor resection. 
A

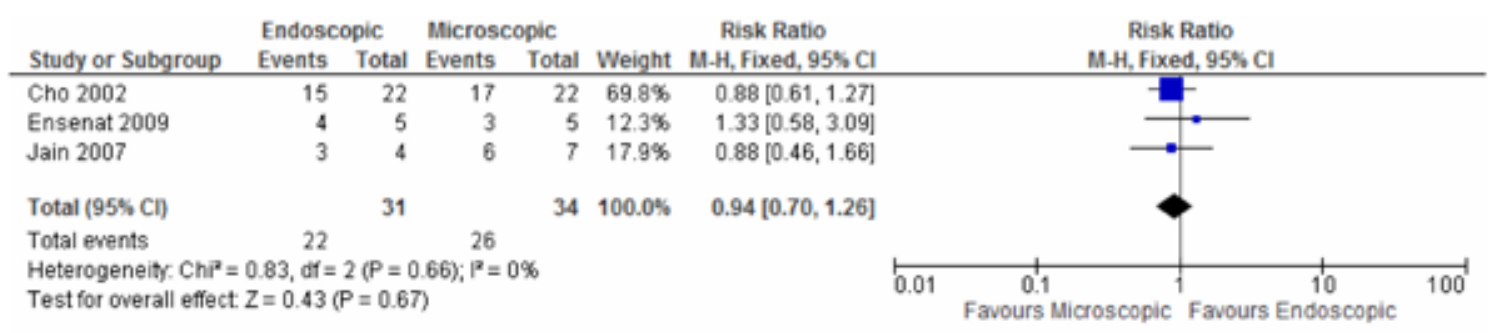

B

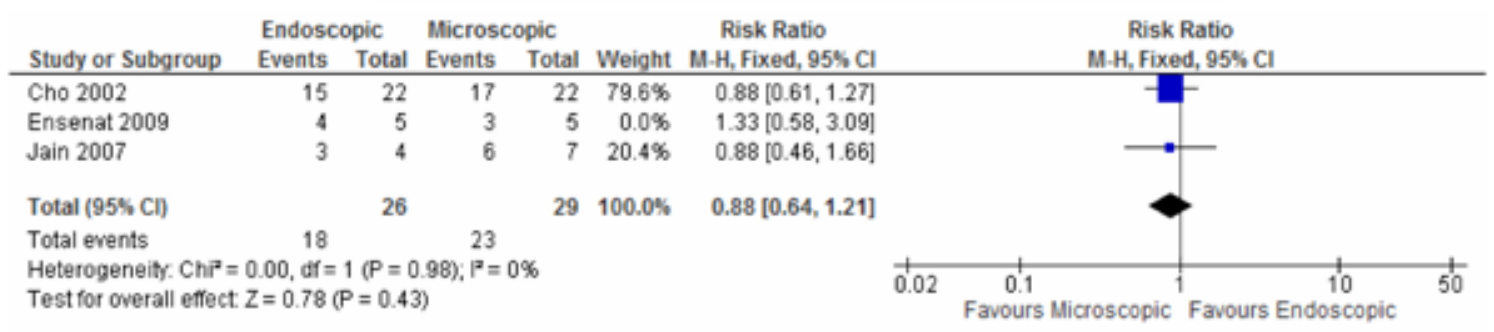

Figure 3. Meta-analysis of achievement of biochemical control of functioning adenomas, A-B. A. Meta-analysis of randomized and non-randomized studies. B. Meta-analysis of two randomized studies

A

\begin{tabular}{|c|c|c|c|c|c|c|c|c|c|}
\hline \multirow[b]{2}{*}{ Study or Subgroup } & \multicolumn{2}{|c|}{ Endoscopic } & \multicolumn{2}{|c|}{ Microscopic } & \multirow{2}{*}{ Weight } & \multirow{2}{*}{$\begin{array}{c}\text { Risk Ratio } \\
\text { M-H, Random, } 95 \% \mathrm{Cl} \\
\end{array}$} & \multirow{2}{*}{\multicolumn{2}{|c|}{$\begin{array}{c}\text { Risk Ratio } \\
\text { M.H, Random, } 95 \% \mathrm{Cl}\end{array}$}} & \\
\hline & Events & Total & Events & Total & & & & & \\
\hline Cho 2002 & 1 & 22 & 6 & 22 & $11.6 \%$ & $0.17[0.02,1.27]$ & & & \\
\hline Ensenat 2009 & 5 & 25 & 5 & 23 & $23.6 \%$ & $0.92[0.31,2.77]$ & & & \\
\hline Jain 2007 & 2 & 10 & 7 & 10 & $20.1 \%$ & $0.29[0.08,1.05]$ & & & \\
\hline Kahilogullari 2013 & 2 & 25 & 18 & 25 & $19.4 \%$ & $0.11[0.03,0.43]$ & & & \\
\hline Little 2014 & 5 & 67 & 11 & 99 & $25.3 \%$ & $0.67[0.24,1.85]$ & & & \\
\hline Total $(95 \% \mathrm{CI})$ & & 149 & & 179 & $100.0 \%$ & $0.37[0.16,0.83]$ & & & \\
\hline Total events & 15 & & 47 & & & & & & \\
\hline $\begin{array}{l}\text { Heterogeneity. Taus } \\
\text { Test for overall effect }\end{array}$ & $\begin{array}{l}0.42 ; \mathrm{Chi} \\
\mathrm{Z}=2.42\end{array}$ & $\begin{array}{l}=7.93, \\
=0.02\end{array}$ & $d f=4(P$ & 0.09); & $I^{2}=50 \%$ & & $\begin{array}{cc}0.01 & 0.1 \\
\text { Favours Endo }\end{array}$ & $\frac{10}{11}=$ & $\begin{array}{r}100 \\
\text { scopic }\end{array}$ \\
\hline
\end{tabular}

B



Figure 4. Meta-analysis of postoperative complications; A-B. A. Meta-analysis of randomized and non-randomized studies. B. Meta-analysis of two randomized studies. 
Quality of life was not evaluated in the included studies. The two randomized studies evaluated time of operation and endoscopic TSS was performed faster than microscopic TSS in both of them. However, meta-analysis could not be performed in this outcome because only one study indicated SD.

\section{Quality of evidence}

As shown in Table 2, the quality of evidence according to GRADE approach was performed only for two common outcomes in the two randomized studies (postoperative complications and achievement of biochemical control of functioning adenomas) $(6,26)$.

Despite that the randomized studies did not have lost of follow-up, the GRADE approach for our outcomes "postoperative complications" and "achievement of biochemical control of functioning adenomas" was necessary to rate down for the risk of bias, because only the study by Jain and cols. (26) mentioned randomization process, while concealment allocation was not clear in neither of them. The sensitivity analysis of these outcomes excluding non-randomized controlled trials showed a RR was 0.23 (CI: 0.08-0.70) and 0.88 (CI: 0.64-1, 21) respectively (Figures $3 \mathrm{~B}$ and 4B). There was no need to rate down for inconsistency, as no heterogeneity at the meta-analysis results was observed. Similarly, it was not necessary to rate down for indirectness for both outcomes. Imprecision was rated down for "achievement of biochemical control of functioning adenomas", because the 95\% CI did not exclude a RR of 1 . Concerning publications bias, rate down of quality was necessary due to small number of randomized controlled trials. Quality of evidence for postoperative complications was low and for achievement of biochemical control of functioning adenomas was very low.

\section{DISCUSSION}

With recent advances on endoscopic sinus surgery, the use of endoscope to reach the sella turcica has emerged as an alternative method for resection of pituitary tumors (29). Additionally, it has been suggested that the endoscopic surgery, in comparison with microscope approach, may be associated with more gross-total tumor resection, shorter hospital stay, shorter operation time, lower estimated blood lose, low complication rates and better endocrine outcomes (30). However, there is no clear evidence that this concept is true and available results from published studies are still controversial.

Atkinson and cols. (2) published a retrospective comparison between these two surgical modalities. They found shorter anesthesia time, hospital stay and less blood loss with the endoscopic technique. However, they found no difference in postoperative complications or hormonal disease control. The authors concluded that success rate was more related to the surgeon experience than to the surgery technique itself.

Considering nonfunctioning pituitary adenomas (NFPAs), Messerer and cols. (3) published a retrospective study and demonstrated a greater total tumor resection rate with the endoscopic technique ( $74 \%$ vs $50 \%, \mathrm{p}=0.002)$. On the other hand, Cappabianca and cols. (5) conducted a comparison between a prospective group of patients operated with endoscope and a retrospective group operated with microscope and found no difference between them. However, hospital stay was shorter in the endoscopic group $(3.1 \pm 0.4$ vs $6.2 \pm 0.3$ days, $\mathrm{p}<0,001)$.

Choe and cols. (30) performed a study that included 17 acromegalic pacients; eight operated by the microscopic approach from 1997 to 2004 and nine by the endoscopic approach from 2004 to 2007 .

Table 2. GRADE approach for primary outcomes

\begin{tabular}{|c|c|c|c|c|c|c|c|c|}
\hline \multirow{2}{*}{ Patient outcomes } & \multicolumn{5}{|c|}{ Quality of assessment } & \multicolumn{3}{|c|}{ Summary of findings } \\
\hline & Risk of bias & Inconsistency & Indirectness & Imprecision & $\begin{array}{c}\text { Publication } \\
\text { Bias }\end{array}$ & $\begin{array}{c}\text { Relative effect } \\
\text { (95\% Cl) }\end{array}$ & RRR & Quality \\
\hline $\begin{array}{l}\text { Postoperative } \\
\text { complications } \\
2 \text { RCTs (55) }\end{array}$ & Serius $(-1)$ & $\begin{array}{c}\text { No } \\
\text { inconsistency }\end{array}$ & Direct & $\begin{array}{c}\text { No } \\
\text { imprecision }\end{array}$ & $\begin{array}{c}\text { Serius } \\
(-1)\end{array}$ & $\begin{array}{c}\text { RR } 0.23 \\
(0.08-0.7)\end{array}$ & $77 \% *$ & ++ , low quality \\
\hline $\begin{array}{l}\text { Achievement of } \\
\text { biochemical control of } \\
\text { functioning adenomas, } \\
2 \text { RCTs (55) }\end{array}$ & Serius $(-1)$ & $\begin{array}{c}\text { No } \\
\text { inconsistency }\end{array}$ & Direct & $\begin{array}{c}\text { Serious } \\
(-1)\end{array}$ & $\begin{array}{c}\text { Serius } \\
(-1)\end{array}$ & $\begin{array}{c}\text { RR } 0.88 \\
(0.64-1.21)\end{array}$ & $12 \%^{* *}$ & $\begin{array}{c}+ \text {, very low } \\
\text { quality }\end{array}$ \\
\hline
\end{tabular}

* In favor of interventional group. ** In favor of control group. Low quality evidence: the authors are not confident in the effect estimate and the true value may be substantially different from it. Very low quality evidence: the authors do not have any confidence in the estimate and it is likely that the true value is substantially different from it. 
In the endoscopic group, eight patients had full tumoral resection and obtained criteria for cure, while the same outcomes were seen in only three patients in the microscopic group.

Our systematic review included only prospective randomized and non-randomized controlled studies comparing the two TSS techniques, because retrospective studies are more likely to provide biased information. In addition, in almost all published retrospective comparisons, the microscopic surgeries were done chronologically before the endoscopic surgeries. As TSS efficiency is correlated to the surgeons' ability and experience, the superiority of one specific technique over the other may be attributed much more for the accumulated time of neurosurgeon experience than the technique itself.

Our primary outcome of total tumor resection was only possible to be evaluated in two studies $(26,27)$. Jain and cols. (26) considered tumor complete excision by direct visualization of sella turcica (sella turcica was inspected for residual tumor with a 308 endoscope) and Enseñat and cols. (27) defined total resection by no visualization of tumor remnants in a MRI carried out three months after surgery. Although the metaanalysis of this endpoint showed a RR of 1.45 favoring intervention group, with an $\mathrm{I}^{2}=0 \%$ it was not possible to exclude RR of 1.0 (CI: 0.87-2.44) in the 95\% CI.

Achievement of biochemical control of functioning adenomas was evaluated in three studies (6,26-27). Cho and Liau (6) considered normalization of prolactin levels as hormonal control in patients with prolactinomas. Enseñat and cols. (27) used GH levels less than $1 \mathrm{ng} / \mathrm{mL}$ after oral glucose tolerance test with normal IGF-1 as criteria for cure in acromegaly, prolactin levels $<30$ $\mathrm{mg} / \mathrm{dL}$ in women and $<15 \mathrm{mg} / \mathrm{dL}$ in men for cure in prolactinomas and normal urinary free cortisol for cure in Cushing's disease. Jain and cols. (26) did not mention the criteria used to determine the biochemical control. The meta-anlysis of this endpoint showed a risk ratio of 0.94 , favoring control group. However, the 95\% CI did not exclude a RR of 1 (0.7-1.26), even with sensitivity analysis excluding non-randomized studies. These findings demonstrated a serious imprecision, and based on GRADE approach, the quality of evidence was very low, with a substantial chance that the true value is considerably different from what we observed.

The safety of the two TSS approaches was evaluated by comparison of postoperative complications rates in the five studies included in our review. The analysis was related to all complications reported at postoperative time, since it was not possible to determine the risks for each complication separately in the studies. The meta-analysis showed a relative risk of $0.37(95 \%$ CI: 0.16-0.83), resulting that endoscopic surgery reduced in $63 \%$ the chance of surgical complications in relation to the microscopic technique, but with an $\mathrm{I}^{2}=50 \%$. We have tried to solve this heterogeneity performing a sensitivity analysis with the exclusion of non-randomized controlled trials. The significance was maintained in favor of endoscopic group, with a RR of 0.23 (CI: 0.08-0.70) and $\mathrm{I}^{2}=0$. However, applying GRADE approach, the quality of evidence was not high, due to small number of randomized studies and the lack of information related to process of randomization and concealment allocation.

Other systematic reviews comparing endoscopic and microscopic TSS have been previously published (31$35)$. Two $(6,26)$ studies included in our meta-analysis also appear in some of the previous published systematic reviews (32-33), while the other three $(4,27,28)$ are included only in our study. Some reports used either Medline or Medline and Embase electronic databases to retrieve published studies (33-35). In contrast with our review, all of them had language restriction (English) and predominantly included retrospective studies in their analysis. Moreover, most of them did not specify the number of reviewers who participated on quality assessment process, the potential causes of heterogeneity among the studies and the randomeffects model. In three systematic reviews, the authors compared the results of endoscopic TSS in a particular study with those of microscopic TSS performed in another unrelated study (31-34).

In summary, based on prospective controlled studies, our review did not find a significant difference between endoscopic and microscopic TSS in relation to pituitary tumor resection rates and achievement of biochemical control of functioning pituitary adenomas. Postoperative complications seem to be less frequent with the endoscopic procedure. However, the quality of evidence for these outcomes was low or very low according to GRADE system. Due to this low evidence level and low number of observations, the results of our meta-analysis should not be viewed as a final proof of inferiority or superiority of one approach in relation to the other at this moment. New randomized trials with larger number of patients, more precise comparisons, and long-term outcomes, are needed. 
Funding: this work was partially supported by Sao Paulo State Research Foundation (Fapesp); Grant \#2012/14761-0.

Acknowledgements: we thank Brazilian Cochrane Centre; specially Gustavo Porfirio.

Disclosure: no potential conflict of interest relevant to this article was reported.

\section{REFERENCES}

1. Swearingen B. Update on pituitary surgery. J Clin Endocrinol Metab. 2012;97:1073-81.

2. Atkinson JLD, Young WF, Meyer FB, Davis DH, Nippoldt TB, Erickson D, et al. Sublabial transseptal vs transnasal combined endoscopic microsurgery in patients with Cushing disease and MRI-depicted microadenomas. Mayo Clin Proc. 2008;83:550-3.

3. Messerer M, De Battista JC, Raverot G, Kassis S, Dubourg J, Lapras $V$, et al. Evidence of improved surgical outcome following endoscopy for nonfunctioning pituitary adenoma removal. Neurosurg Focus. 2011;30:E11.

4. Little AS, Chapple K, Jahnke H, White WL. Comparative inpatient resource utilization for patients undergoing endoscopic or microscopic transsphenoidal surgery for pituitary lesions. J Neurosurg. 2014;121(1):84-90.

5. Cappabianca P, Alfieri A, Colao A, Ferone D, Lombardi G, de Divitiis $E$, et al. Endoscopic endonasal transsphenoidal approach: an additional reason in support of surgery in the management of pituitary lesions. Skull Base Surg. 1999;9(2):109-17.

6. Cho D-Y, Liau W-R. Comparison of endonasal endoscopic surgery and sublabial microsurgery for prolactinomas. Surg Neurol. 2002;58(6):371-5.

7. The Cochrane Collaboration. Cochrane Handbook for Systematic Reviews of Interventions Version 5.1.0 [updated March 2011]. 2011. 2011.

8. Guyatt GH, Oxman AD, Kunz R, Vist GE, Falck-YtterY, Schünemann HJ. What is "quality of evidence" and why is it important to clinicians? BMJ Br Med J. 2008;336:995-8.

9. Guyatt G, Oxman AD, Akl EA, Kunz R, Vist G, Brozek J, et al. GRADE guidelines: 1. Introduction - GRADE evidence profiles and summary of findings tables. J Clin Epidemiol. 2011;64:383-94.

10. Guyatt GH, Oxman AD, Vist G, Kunz R, Brozek J, Alonso-Coello P, et al. GRADE guidelines: 4 . Rating the quality of evidence - Study limitations (risk of bias). J Clin Epidemiol. 2011;64(4):407-15.

11. Guyatt GH, Oxman AD, Kunz R, Brozek J, Alonso-Coello P, Rind $D$, et al. GRADE guidelines 6 . Rating the quality of evidence Imprecision. J Clin Epidemiol. 2011;64(12):1283-93.

12. Guyatt GH, Oxman AD, Montori V, Vist G, Kunz R, Brozek J, et al. GRADE guidelines: 5 . Rating the quality of evidence - Publication bias. J Clin Epidemiol. 2011;64(12):1277-82.

13. Guyatt GH, Oxman AD, Kunz R, Woodcock J, Brozek J, Helfand $M$, et al. GRADE guidelines: 7. Rating the quality of evidence Inconsistency. J Clin Epidemiol. 2011;64(12):1294-302.

14. Guyatt GH, Oxman AD, Kunz R, Woodcock J, Brozek J, Helfand $M$, et al. GRADE guidelines: 8 . Rating the quality of evidence Indirectness. J Clin Epidemiol. 2011;64(12):1303-10.

15. Oosmanally N, Paul JE, Zanation AM, Ewend MG, Senior BA, Ebert CS Jr. Comparative analysis of cost of endoscopic endonasal minimally invasive and sublabial-transseptal approaches to the pituitary. Int Forum Allergy Rhinol. 2011;1(4):242-9.

16. Kassis S, De Battista JC, Raverot G, Jacob M, Simon E, Rabilloud $M$, et al. Endoscopy versus microsurgery: results in a consecutive series of nonfunctioning pituitary adenomas. Neurochirurgie. 2009;55:607-15.

17. Kabil MS, Eby JB, Shahinian HK. Fully endoscopic endonasal vs. transseptal transsphenoidal pituitary surgery. Minim Invasive Neurosurg. 2005;48:348-54.

18. Ogawa T, Matsumoto $K$, Nakashima T, Okano M, OnoY, Fukushima $\mathrm{K}$, et al. Hypophysis surgery with or without endoscopy. Auris Nasus Larynx. 2001;28(2):143-9.

19. Badie B, Nguyen P, Preston JK. Endoscopic-guided direct endonasal approach for pituitary surgery. Surg Neurol. 2000;53(2):168-72; discussion 172-3.

20. Shah S, Har-El G. Diabetes insipidus after pituitary surgery: incidence after traditional versus endoscopic transsphenoidal approaches. Am J Rhinol. 15(6):377-9.

21. Kawamata $T$, Iseki $H$, Ishizaki $R$, Hori $T$. Minimally invasive endoscope-assisted endonasal trans-sphenoidal microsurgery for pituitary tumors: experience with 215 cases comparing with sublabial trans-sphenoidal approach. Neurol Res. 2002;24(3): 259-65.

22. Razak AA, Horridge M, Connolly DJ, Warren DJ, Mirza S, Muraleedharan $\mathrm{V}$, et al. Comparison of endoscopic and microscopic trans-sphenoidal pituitary surgery: early results in a single centre. Br J Neurosurg. 2013;27:40-3.

23. Massimi L, Rigante $M$, D'Angelo $L$, Paternoster $G$, Leonardi $P$, Paludetti G, et al. Quality of postoperative course in children: endoscopic endonasal surgery versus sublabial microsurgery. Acta Neurochir (Wien). 2011;153(4):843-9.

24. Enseñat J, Ortega A, Topcewski T, Vilalta J, Obiols G, Sahuquillo JMJ. Valor predictivo de la clasificación de Knosp en el grado de resección quirúrgica de los macroadenomas invasivos. Estudio prospectivo de una serie de 23 casos. Neurocirugía. 2006;519-26.

25. Eloy P, Watelet JB, Donckier J, Gustin T, Gaudon IP, Collet S, et al. Endoscopic and microscopic paraseptal transsphenoidal approach to the sella turcica. Rhinology. 2005;43(4):271-6.

26. Jain AK, Gupta AK, Pathak A, Bhansali A, Bapuraj JR. Excision of pituitary adenomas: randomized comparison of surgical modalities. Br J Neurosurg. 2007;21(4):328-31.

27. Enseñat J, Quesada JL, Aparicio J, Pàmies $C$, Barber $X$, Topczewski $\mathrm{T}$, et al. Comparación del abordaje sublabial transesfenoidal microquirúrgico frente al abordaje endonasal transesfenoidal endoscópico. Estudio prospectivo de 50 pacientes. Neurocirugía. 2009;20(4):335-45.

28. Kahilogullari G, Beton S, Al-Beyati ESM, Kantarcioglu O, Bozkurt $M$, Kantarcioglu E, et al. Olfactory functions after transsphenoidal pituitary surgery: endoscopic versus microscopic approach. Laryngoscope. 2013;123(9):2112-9.

29. Storr HL, Drake WM, Evanson J, Matson M, Berney DM, Grossman $A B$, et al. Endonasal endoscopic transsphenoidal pituitary surgery: early experience and outcome in paediatric Cushing's disease. Clin Endocrinol (Oxf). 2014;80(2):270-6.

30. Choe J-H, Lee K-S, Jeun S-S, Cho J-H, Hong Y-K. Endocrine outcome of endoscopic endonasal transsphenoidal surgery in functioning pituitary adenomas. $\mathrm{J}$ Korean Neurosurg. 2008;44(3):151-5.

31. Gao Y, Zhong C, Wang Y, Xu S, Guo Y, Dai C, et al. Endoscopic versus microscopic transsphenoidal pituitary adenoma surgery: a meta-analysis. World J Surg Oncol. 2014;12:94.

32. Ammirati M, Wei L, Ciric I. Short-term outcome of endoscopic versus microscopic pituitary adenoma surgery: a systematic review and meta-analysis. J Neurol Neurosurg Psychiatry. 2013;84(8):843-9.

33. DeKlotz TR, Chia SH, Lu W, Makambi KH, Aulisi E, Deeb Z. Meta-analysis of endoscopic versus sublabial pituitary surgery. Laryngoscope. 2012;122(3):511-8. 
34. Tabaee A, Anand VK, Barrón Y, Hiltzik DH, Brown SM, Kacker A, et al. Endoscopic pituitary surgery: a systematic review and metaanalysis. J Neurosurg. 2009;111(3):545-54.
35. Komotar RJ, Starke RM, Raper DMS, Anand VK, Schwartz TH. Endoscopic endonasal compared with microscopic transsphenoidal and open transcranial resection of giant pituitary adenomas. Pituitary. 2012;15(2):150-9. 